\title{
(2) OPEN ACCESS \\ Impact of a comprehensive tobacco control policy package on acute myocardial infarction and stroke hospital admissions in Beijing, China: interrupted time series study
}

\author{
Yunting Zheng, ${ }^{1}$ Yiqun $\mathrm{Wu}_{1}{ }^{2}$ Mengying Wang, ${ }^{2}$ Zijing Wang, ${ }^{2}$ Siyue Wang, ${ }^{2}$ \\ Jiating Wang, ${ }^{2}$ Junhui $\mathrm{Wu}_{1}{ }^{2} \mathrm{TaO} \mathrm{Wu}_{1}{ }^{2}$ Chun Chang, ${ }^{9}$ Yonghua Hu ${ }^{2}{ }^{2}$
}

\begin{abstract}
- Additional material is published online only. To view please visit the journal online (http://dx.doi.org/10.1136/ tobaccocontrol-2020-055663).

'Department of Social Medicine and Health Education, School of Public Health, Peking University Health Science Center, Beijing, China

${ }^{2}$ Department of Epidemiology and Biostatistics, School of Public Health, Peking University Health Science Center, Beijing, China
\end{abstract}

\section{Correspondence to}

Dr Yonghua Hu, Department of Epidemiology and Biostatistics, School of Public Health, Peking University Health Science Centre, Beijing 100191, China; yhhu@bjmu.edu.cn and Dr Chun Chang, Department of Social Medicine and Health Education, School of Public Health, Peking University Health Science Centre, Beijing, China; changchun@bjmu.edu.cn

YZ and YW contributed equally.

$\mathrm{YZ}$ and $\mathrm{YW}$ are joint first authors.

Received 27 January 2020 Revised 16 April 2020

Accepted 21 April 2020 Published Online First 15 July 2020

\begin{abstract}
Objective To evaluate a comprehensive tobacco control policy package on hospital admissions for acute myocardial infarction (AMI) and stroke in a global city. Design Interrupted time series study.

Setting Beijing, China.

Population $31707 \mathrm{AMI}$ and 128116 stroke hospital admissions recorded by the Beijing Medical Claim Data for Employees in 17.7 million residents from January 2013 to June 2017
\end{abstract}

Intervention The policy package including all components of MPOWER has been implemented since June 2015.

Main outcome measures The immediate change of AMI and stroke hospital admissions and the annual change in the secular trend.

Results There was a secular increase trend for the crude hospital admission rates of AMI and stroke during the observational period. After implementation of the policy, immediate reductions were observed in the hospital admissions for both AMI $(-5.4 \%, 95 \% \mathrm{Cl}$ $-10.0 \%$ to $-0.5 \%)$ and stroke $(-5.6 \%, 95 \% \mathrm{Cl}-7.8 \%$ to $-3.3 \%)$. In addition, the secular increase trend for stroke was slowed down by $-15.3 \%$ (95\% Cl -16.7\% to $-13.9 \%$ ) annually. Compared with the hypothetical scenario where the policy had not taken place, an estimated 18137 (26.7\%) stroke hospital admissions had been averted during the 25 months of postpolicy period.

Conclusions The results indicated significant health benefits on cardiovascular morbidity after the Beijing tobacco control policy package, which highlighted the importance for a comprehensive tobacco control policy at the national level in China. Similar tobacco control policy which consists of all components of MPOWER is urgently needed in other areas, especially in settings with high tobacco consumption, to achieve greater public health gains.

\section{INTRODUCTION}

Tobacco is responsible for about 8 million deaths each year, accounting for $14 \%$ of all deaths from non-communicable diseases and $5 \%$ of all deaths from communicable diseases. ${ }^{1}$ The effects of secondhand smoke (SHS) exposure have been found to be nearly as large (80\%-90\%) as those of chronic active smoking. ${ }^{2}$ To compete for the huge disease burden, the WHO adopted the WHO Framework Convention on Tobacco Control (WHO FCTC) in
$2003^{3}$ and introduced six MPOWER measures to implement the WHO FCTC effectively. ${ }^{4}$ By 2019 , about 5 billion people in 139 countries are covered by at least one of the key interventions. ${ }^{5}$ Due to the efforts, tobacco consumption has decreased in high-income and European countries, ${ }^{6}$ and the prevalence of current smoking among adults as well as indoor SHS exposure has declined globally. ${ }^{78}$ According to $\mathrm{WHO}$, the number of tobacco-related deaths would have 2 million more each year globally without the intervention, ${ }^{9}$ where the largest number of deaths averted happened as the result of increased cigarette taxes and smoke-free air laws. ${ }^{10}$

China is the world's largest consumer of tobacco, with the estimated consumption larger than the next 39 highest tobacco-consuming countries combined. ${ }^{11}$ There were over 300 million smokers with a smoking prevalence of $50.5 \%$ among males and $2.1 \%$ among females in $2018 .{ }^{12}$ It was estimated that $68.1 \%$ of non-smokers in China are exposed to SHS at least once a day. ${ }^{12}$ In 2017, smoking caused about 2 million deaths in China. ${ }^{13}$ China signed the WHO FCTC in 2003 and ratified it in 2005, but it has been slow in implementing the obligations. ${ }^{14}$ At the national level, the tobacco control legislation compromised to economic interests, ${ }^{15}$ and there is no smoking ban in public places, ${ }^{15} 16$ though progress has been made in banning tobacco advertisement ${ }^{17}$ and strengthening cigarette package warning. ${ }^{18}$ At the subnational level, some cities in China enact smoke-free directives, including Beijing. In 2008, Beijing initiated a smoking ban in 11 types of public places for the smoke-free Olympics. ${ }^{19}$ Seven years later in June 2015, Beijing enforced the Beijing Municipal Tobacco Control Regulation. ${ }^{20}$ Almost simultaneously, the National Tobacco Tax Reform was initiated in May 2015, ${ }^{21}$ which together formulated the Beijing comprehensive tobacco control policy package by midyear of 2015 .

The 2015 Beijing policy package comprises all components of MPOWER, including a smoking ban in all indoor and four outdoor public places, a raise of tobacco tax, a ban of advertisement, promotion, sponsorship of tobacco and an establishment of a cessation support system and media campaign. This is the strongest tobacco control policy most in line with the WHO framework in the country. ${ }^{22}$ It was expected to function under the WHO FCTC frame to reduce tobacco consumption by influencing the tobacco supply and demand (figure 1). According to 


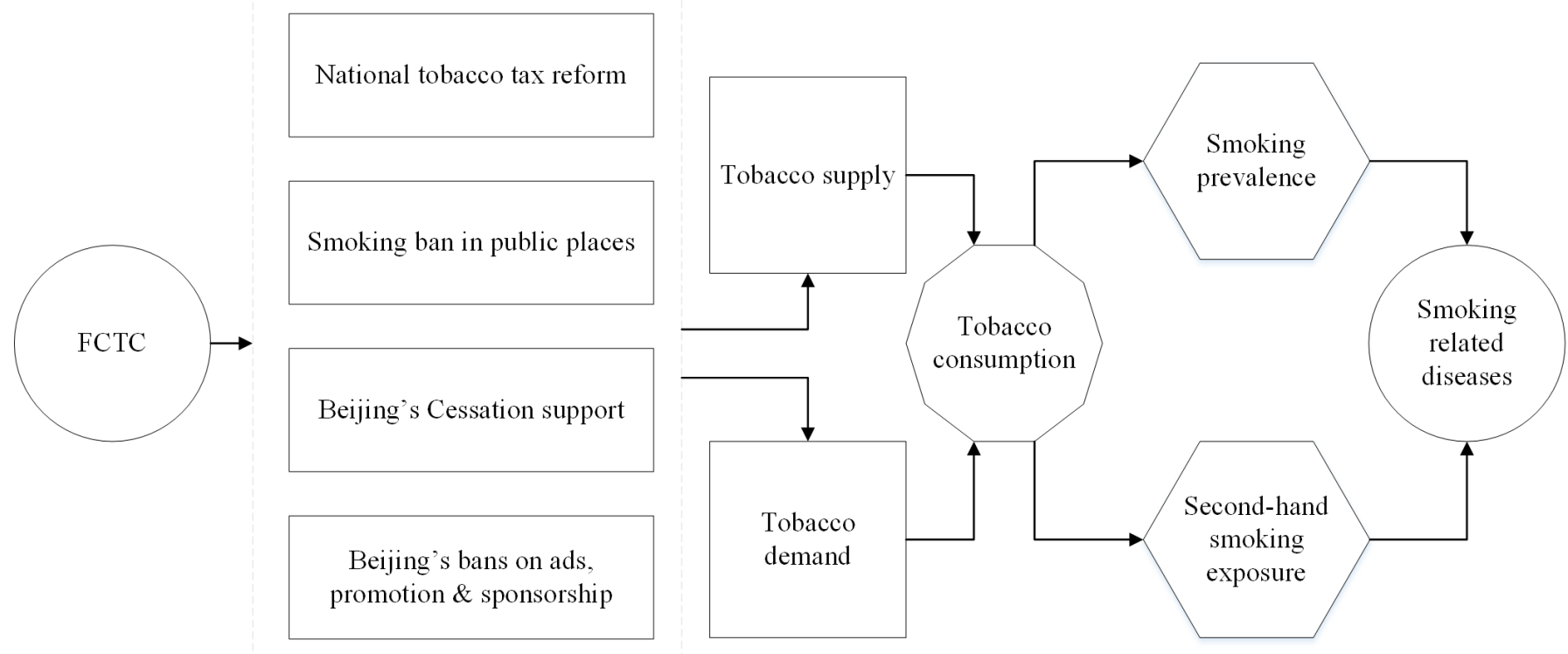

Figure 1 Logic model for conceptualising the impact of Beijing's comprehensive tobacco control policy package on smoking-related diseases. FCTC, Framework Convention on Tobacco Control.

the statistics, there was a decrease of more than 4 billion $(9.1 \%)$ cigarette consumption 1 year after the policy. ${ }^{23}$ The smoking prevalence and SHS exposure decreased subsequently from 2014 to 2017 , with a reduction of $20.3 \%$ and $25.6 \%$, respectively. ${ }^{24}$ The reduction in tobacco exposure was expected to bring an impact on the occurrence of smoking-related diseases, however, the health benefit of this comprehensive policy package remains unclear. This study aimed to evaluate the health impact of the 2015 Beijing tobacco control policy package during 54 months (25 months for the postpolicy period).

Cardiovascular diseases were the leading cause of smokingattributable death globally. ${ }^{25}$ Abundant studies, as well as the Cochrane Systematic Review 2016 on legislative smoking bans, ${ }^{26}$ showed decreases in the burden of cardiovascular diseases after smoking bans in mortality ${ }^{27-32}$ and morbidity. ${ }^{29} 3033-52$ As studies showed the decrease in the incidence of cardiovascular disease right after the smoking-free ban on public places was biologically plausible ${ }^{53-55}$ significant reductions in the hospital admissions for cardiovascular diseases were reported. ${ }^{33} 34$ 37-40 47-52 5657 These studies were mostly from North America, Europe and Latin America, and showed consistent results for acute myocardial infarction (AMI), 3334 37-40 475152 while studies for stroke are limited and results were inconsistent. ${ }^{374} 49$ Globally, the greatest estimated lifetime risk of stroke was in East Asia, especially the highest risk in men was in China. ${ }^{58}$ Take the large volume of tobacco consumption, high prevalence of smoking and SHS exposures, and a large population with risk factors in China into account, introducing a comprehensive tobacco control policy package which consists of all components of MPOWER may obtain significant health benefits on cardiovascular diseases. 5960 Therefore, this study aimed to evaluate the impact of the 2015 Beijing tobacco control policy package on hospital admissions for AMI and stroke. The results will provide evidence on the health benefit from the comprehensive tobacco control policies to inform policymakers regarding the decision-making on tobacco control issue and the management of public health diseases.

\section{METHODS}

\section{Study design}

An interrupted time series (ITS) design was used in this study. ITS is a valuable design for evaluating population-level health interventions over a clearly defined time period, ${ }^{61}$ such as the tobacco control law. ${ }^{6462}$ The intervention evaluated was the Beijing comprehensive tobacco control policy package implemented from June 2015, which included all components of MPOWER. Table 1 presents the comparison of MPOWER adoption in Beijing before and after the policy in 2015. The main health outcomes evaluated were hospital admissions of AMI and stroke. Based on the ITS design, a time series of the hospital admission rates with the underlying trend is 'interrupted' by the policy in June 2015. Under the hypothetical scenario, the policy had not taken place and the underlying trend of hospital admissions had been kept unchanged, providing a comparison with the actual trend in the postpolicy period. The impact of the policy, therefore, can be evaluated by examining change occurring in the postpolicy period. According to our hypothesis, the hospital admission rates for AMI and stroke will decrease or the increasing trend will slow down after the enforcement of the policy package. While for diseases that were not immediately affected by the law, the hospital admissions will not change. Therefore, injury and poison employed as control diseases were also tested in the study.

The observation period in this study covered 54 months from January 2013 to June 2017, including 29 months before and 25 months after the enforcement of the policy package. If the policy did have effects, when resetting the enforcement date artificially during the prepolicy period the effects would disappear. Thus, 
Table 1 A comparison of MPOWER adoption in Beijing before and after June 2015

\begin{tabular}{|c|c|c|c|}
\hline MPOWER tools & Intervention & Pre-June 2015 & Post-June 2015 \\
\hline $\begin{array}{l}\text { Monitor tobacco use and prevention } \\
\text { policies. }\end{array}$ & Conduct Beijing's adult survey & Year of the survey: 2014 & Year of the survey: 2016 \\
\hline Protect people from tobacco use. & Smoke-free air laws & $\begin{array}{l}\text { Stipulation } \\
\text { Smoking banned in eight public places: for } \\
\text { example, health facilities }\end{array}$ & $\begin{array}{l}\text { Legislation } \\
\text { Smoking banned in all indoor public places, } \\
\text { workplaces, public transportation and four } \\
\text { outdoor places }\end{array}$ \\
\hline Offer help to quit tobacco use. & Cessation support & Not available & Cessation clinics and hotlines \\
\hline Warn about the dangers of tobacco. & $\begin{array}{l}\text { Package warning } \\
\text { Media campaign }\end{array}$ & $\begin{array}{l}\text { Text only } \\
\text { Mass media }\end{array}$ & $\begin{array}{l}\text { Text only } \\
\text { Mass media } \\
\text { New media: WeChat account named 'smoke- } \\
\text { free Beijing' }\end{array}$ \\
\hline $\begin{array}{l}\text { Enforce bans on tobacco advertising, } \\
\text { promotion and sponsorship. }\end{array}$ & $\begin{array}{l}\text { Bans on advertising, promotion and } \\
\text { sponsorship }\end{array}$ & Ban on advertising on mass media & $\begin{array}{l}\text { Ban on advertising on mass media and new } \\
\text { media, in public transportation and outdoor } \\
\text { places, towards juveniles }\end{array}$ \\
\hline Raise taxes on tobacco. & $\begin{array}{l}\text { Tobacco tax } \\
\text { Producer: specific tax } \\
\text { Ad valorem tax } \\
\text { Wholesale: specific tax } \\
\text { Ad valorem tax }\end{array}$ & $\begin{array}{l}¥ 0.06 / \text { pack } \\
56 \% \\
\text { No tax } \\
5 \%\end{array}$ & $\begin{array}{l}¥ 0.06 / \text { pack } \\
56 \% \\
0.10 / \text { pack } \\
11 \%\end{array}$ \\
\hline
\end{tabular}

to further support the results, a set of false dates was refixed for comparison in the study.

Variables that may influence the hospital admissions besides the policy were also counted in the study, including seasonality, meteorological factors, ${ }^{63}$ air pollution ${ }^{64}$ and public holidays.

\section{Data collection}

Among the three main basic medical insurance schemes in China, the urban employee basic medical insurance (UEBMI) scheme covered the most population, including all employees in the government, state-owned enterprises, non-government organisations and private entities. In Beijing, the Beijing Medical Claim Data for Employees (BMCDE) keep track of all the medical claim record for approximately 17.7 million working or retired employees covered by UEBMI, accounting for more than $80 \%$ of the whole population. The detail of BMCDE was described elsewhere, ${ }^{65}$ and it has been validated to be useful for epidemiological studies. ${ }^{66}$ In this study, daily hospital admissions for AMI and stroke were obtained from the BMCDE database. AMI was defined as having a primary diagnosis of International Classification of Diseases, Tenth Version (ICD-10) code I21. To avoid the duplicate admissions for the same event, the repeat admissions within a 28-day period were deleted, and only the first admission in one period was retained. Stroke was defined as having a primary diagnosis of ICD-10 codes I60-I64. Hospital admissions for injury and poison (ICD-10 S00-T98) were also extracted as the control condition. All the diagnosis used in this study was the one assigned at discharge.

The meteorological data on daily 24-hour average temperature $\left({ }^{\circ} \mathrm{C}\right)$ and relative humidity (\%) were obtained from the China Meteorological Data Sharing Service System (http://data.cma. $\mathrm{cn} /$ ). Data of all three stations around Beijing (Yanqing District, Mi Yun District and Langfang Shi) were averaged. Particulate matter with aerodynamic diameter $\leq 2.5 \mu \mathrm{m}$ (PM2.5) concentrations was considered as the air pollution confounders in this study. The hourly PM2.5 concentrations $\left(\mu \mathrm{g} / \mathrm{m}^{3}\right)$ were obtained from the US embassy report, which established an ambient air quality monitoring station on the rooftop of the embassy building located in Chaoyang District, Beijing. It was reported that about $79.2 \%$ of Beijing's population resided within a $40 \mathrm{~km}$ radius of the US embassy ambient monitoring station. ${ }^{67}$ The public holidays (New Year's Day, Spring Festival, Qingming Festival, Labor Day, Dragon Boat Festival, Mid-Autumn Festival, National Day) each year were set up according to the information released by the General Office of the State Council of the People's Republic of China (http://english.www.gov.cn).

\section{Statistical analysis}

The crude hospital admission rates with 95\% CIs for both AMI and stroke were calculated as the number of annual hospital admissions divided by the population covered by the UEBMI. Using the residents in the sixth demographic census in 2010 in Beijing as the standard population, age and sex-adjusted rates were further calculated for comparison.

To test whether hospital admission rates changed after the policy package, a segmented Poisson regression model was developed using the ITS design. ${ }^{68}$ All the variables in the model were set up as time series on a weekly basis. The response variable was the weekly number of AMI or stroke hospital admissions. To estimate the admission rate directly, the weekly population size for the employees covered by UEBMI in Beijing was included as an offset variable with a fixed coefficient of 1 . An indicator variable was used in the model to define the policy package, with a value of 0 given to weeks before enforcement and a value of 1 given to weeks after enforcement. The immediate impact of the policy was assessed as the change in rate for admissions. An interaction term between the policy and time was included to estimate the change in the slope of a secular trend in the postpolicy period compared with the prepolicy period. The time used in the interaction was the time elapsed since the start of the intervention. The time was set as 0 when the policy package enforced. A linear predictor for the time was included to quantify the changes in population risk factors, treatment and other secular trends. Seasonality was modelled by a Fourier series of sine and cosine terms. ${ }^{61}$ The number of public holidays in each week was included in the model to account for the differences between weeks. In addition, mean weekly values for temperature, relative humidity and PM2.5 were also adjusted, as penalised splines with the degree of freedom of 4 . The estimated percentage of immediate change and the average annual change in the secular trend were calculated by the coefficient of the policy indicator and the interaction term between time 
and the policy indicator in the model, respectively. The number of averted hospital admissions was calculated as the subtraction between the actual admissions and the predicted number without the influence of the policy.

To assess the effect of the 2018 Beijing policy package in different population subgroups, the data were stratified by age ( $<65$ and $\geq 65$ years) and sex, and separate analyses were conducted in each group. Five false dates for enforcement ranging from January 2014 to January 2015 were used to refit the model for evaluating the true impact.

In the sensitivity analysis, the readmissions within a 28-day period were also included. Furthermore, models including a spline-based smooth temporal trend were also set up to capture the non-linear trend, using a thin plate spline with the degree of freedom of 3. All analyses were conducted in R (V.3.5.1), ${ }^{69}$ and the model was fitted using the 'mgcv' package. ${ }^{70}$

\section{Patient and public involvement}

As the outcome in the analysis was the weekly count of hospital admissions, no members of the public were directly involved in the study design, outcome measures, analysis of data or interpretation of study results. The results of this study will be reported via the media centre of the authors' institutions (www.bjmu. edu.cn) after the publication where the official news will be written under authors' supervision to avoid overinterpretation. Other dissemination includes scientific meetings and mass media (WeChat). No plans exist to involve members of the public in dissemination.

\section{RESULTS}

From 1 January 2013 to 30 June 2017, there were totally 30618 AMI (31519 without readmissions within 28 days) and 127609 stroke hospital admissions among the insured employees aged 18 years and older in Beijing (table 2). The annual crude hospital admission rates were 38.6 and 160.6 per million residents for AMI and stroke, respectively (table 2). A secular increase was observed in the rates of hospital admissions for both AMI and stroke (online supplementary figure 1). More admissions occurred in men and those aged over 65 years for both AMI and stroke (online supplementary table 1 ). A seasonal pattern with higher rates of admission over autumn and winter and lower rates in summer and in January was also observed for the two conditions (online supplementary figure 2).

\section{Changes in hospital admissions}

Right after the enforcement of the policy package, both the hospital admission rates for AMI and stroke decreased significantly. There were about $-5.4 \%(95 \%$ CI $-10.0 \%$ to $-0.5 \%)$ reduction for $\mathrm{AMI}$ and $-5.6 \%$ (95\% CI $-7.8 \%$ to $-3.3 \%$ ) reduction for stroke immediately following the enforcement (figure 2). Additionally, there was an annual change of $-15.3 \%$ (95\% CI $-16.7 \%$ to $-13.9 \%$ ) in the secular trend for a hospital admission rate of stroke whereas no significant change was observed for AMI (figure 2, table 3). Average percentage change on a semesterly basis in hospital admission rates for the two diseases were also provided online supplementary file 1 (online supplementary table 2). While for injury and poison, no significant change was found in hospital admission rates right after the enforcement or the secular trend during the postpolicy period online supplementary table 2 . When setting the enforcement date as several false dates, the immediate and secular changes in the hospital admission rates for AMI and stroke disappeared (online supplementary table 3).

The postpolicy effects in population subgroups were shown in table 3. For the hospital admissions of AMI, the immediate reduction and the change in the secular trend were not significant in all subgroups. For the hospital admissions of stroke, the immediate reduction and the change in the secular trend were seen in all subgroups, except that the immediate reduction in females was not significant $(p=0.125)$.

To verify the results, sensitivity analyses were conducted by considering the secular trend as a non-linear form (online supplementary table 4). The immediate reductions and changes in the gradual trend in the main results remained significant for both AMI and stroke. Furthermore, significant changes in the secular trend of hospital admission for AMI were shown in overall, those under 65 years old and males. When including AMI readmissions within 28 days in analysis, the results did not alter (online supplementary table 5).

\section{Number of hospital admissions prevented}

There would have 15518 expected AMI hospital admissions without the policy during the whole postpolicy period (25 months). The difference $(388,95 \%$ CI -718 to 1495$)$ between the predicted number (red line in figure $3 \mathrm{~A}$ ) and the actual number of hospital admissions (black line in figure 3A) for AMI during the postpolicy period was not significant. Nevertheless, the number of hospital admissions for stroke during the postpolicy period was significantly lower than the counterfactual scenario, as large disparities were seen between the red and black lines in figure 3B. During the whole postpolicy period of 25 months, there would have 67417 expected stroke hospital admissions without the policy. An estimated 18137 (95\% CI 15

Table 2 Annual hospital admission rate (1/100 000) of AMI and stroke in Beijing from 2013 to 2017

\begin{tabular}{|c|c|c|c|c|c|c|}
\hline \multirow[b]{2}{*}{ Year } & \multicolumn{3}{|l|}{ AMI } & \multicolumn{3}{|l|}{ Stroke } \\
\hline & $\begin{array}{l}\text { Hospital admissions, } \\
\mathrm{n}\end{array}$ & $\begin{array}{l}\text { Crude annual rate } \\
(95 \% \mathrm{Cl})\end{array}$ & $\begin{array}{l}\text { Standardised annual } \\
\text { rate }(95 \% \mathrm{Cl})\end{array}$ & $\begin{array}{l}\text { Hospital admissions, } \\
\mathrm{n}\end{array}$ & $\begin{array}{l}\text { Crude annual rate } \\
(95 \% \mathrm{Cl})\end{array}$ & $\begin{array}{l}\text { Standardised annual } \\
\text { rate }(95 \% \mathrm{Cl})\end{array}$ \\
\hline 2013 & 5822 & 37.1 (36.1 to 38.0 ) & 34.5 (33.6 to 35.4 ) & 23062 & 146.8 (144.9 to 148.7$)$ & $138.8(136.9$ to 140.6$)$ \\
\hline 2014 & 6117 & 36.4 (35.5 to 37.3 ) & 33.8 (33.0 to 34.7 ) & 25148 & 149.6 (147.8 to 151.5$)$ & 140.8 (139.1 to 142.6$)$ \\
\hline 2015 & 7063 & 39.5 (38.5 to 40.4$)$ & 36.2 (35.3 to 37.1 ) & 31111 & 173.8 (171.8 to 175.7$)$ & $162.4(160.6$ to 164.3$)$ \\
\hline 2016 & 7751 & 40.6 (39.7 to 41.6 ) & 37.1 (36.2 to 37.9$)$ & 32249 & $169.1(167.3$ to 171.0$)$ & 157.8 (156.0 to 159.5$)$ \\
\hline Total & 30618 & 38.6 (38.2 to 39.0 ) & 35.2 (34.9 to 35.6$)$ & 127609 & 160.6 (159.8 to 161.5$)$ & 149.4 (148.6 to 150.2$)$ \\
\hline
\end{tabular}

The standardised annual rates were age and sex adjusted according to the population in the sixth demographic census in Beijing.

AMI, acute myocardial infarction. 


\section{Original research}
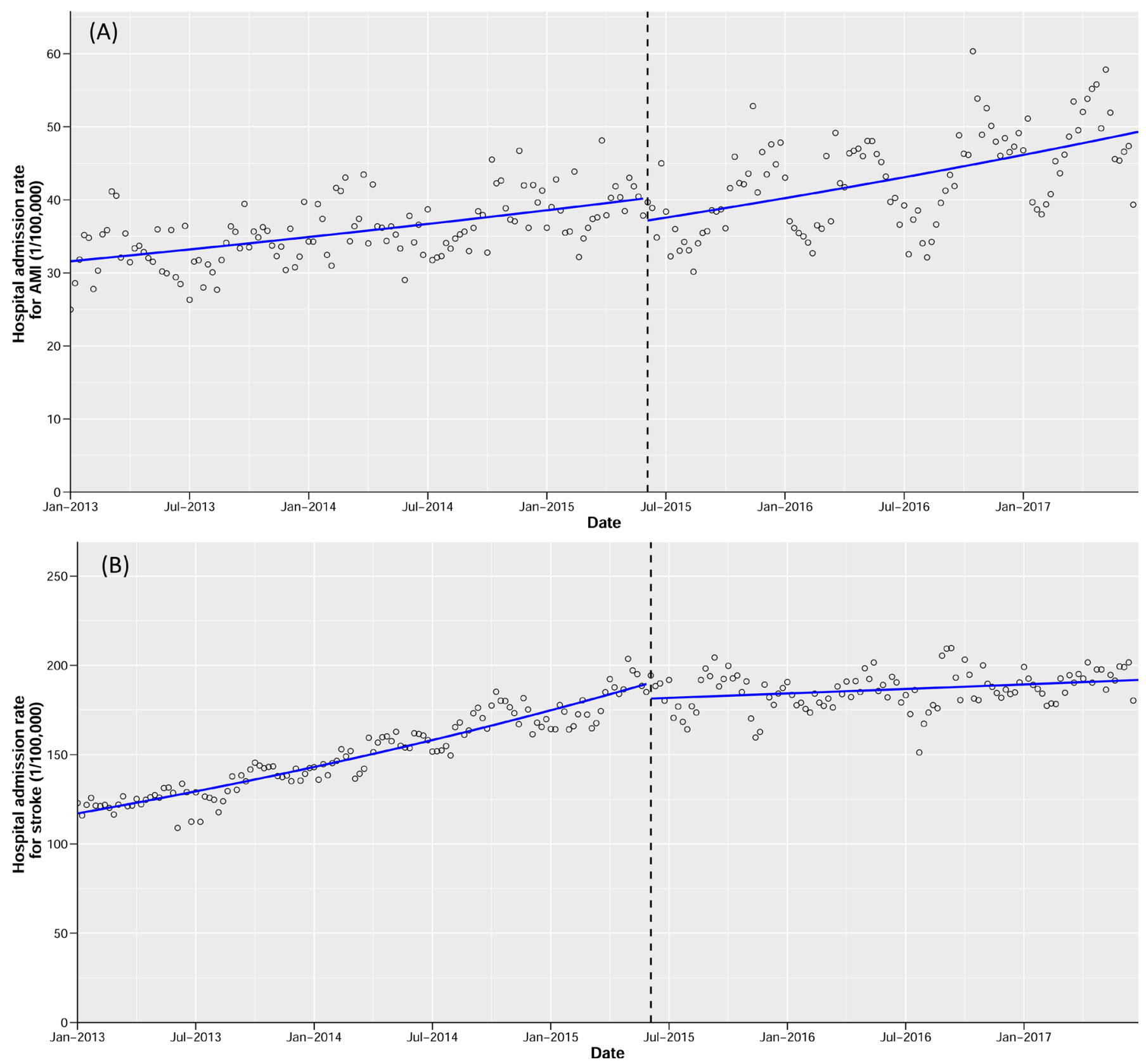

Figure 2 Hospital admission rates of (A) AMI and (B) stroke before and after enforcement of the Beijing tobacco control policy package from January 2013 to June 2017. The dashed vertical line showed the time when the Beijing tobacco control policy package was implemented. The dots showed the hospital admission rates in each week and the blue lines showed the temporal trends of the rates. AMI, acute myocardial infarction.

Table 3 Average percentage change (\%) in hospital admission rates for AMI and stroke after the Beijing tobacco control policy package

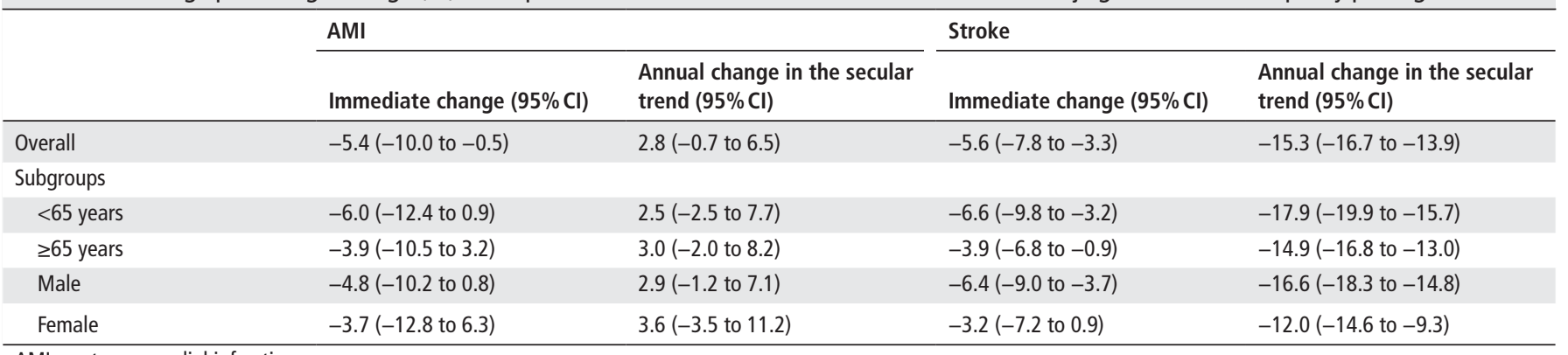



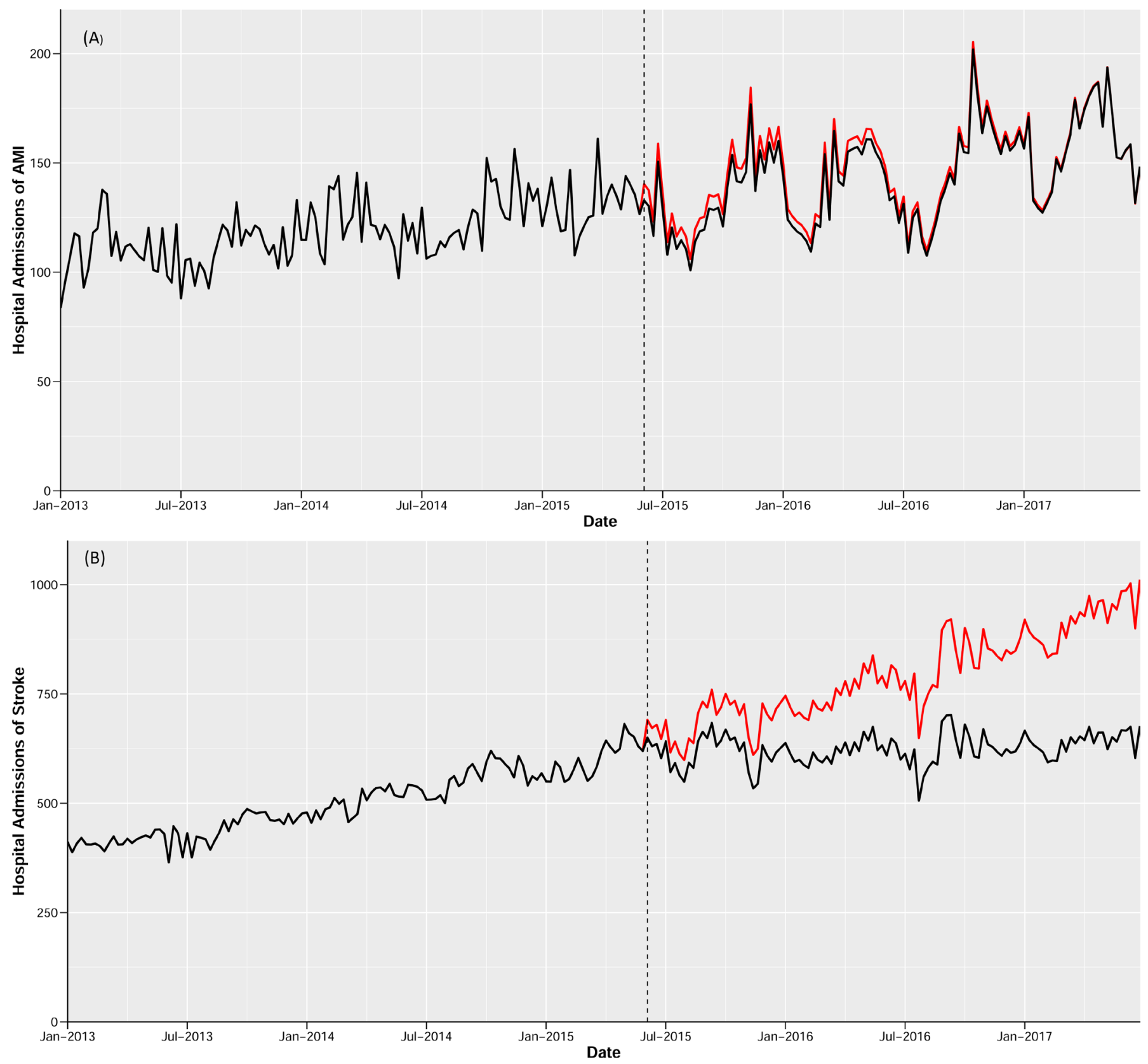

Figure 3 The predicted and actual numbers of hospital admissions for (A) AMI and (B) stroke from January 2013 to June 2017 . Red line predicted hospital admissions without the law. Black line predicted actual hospital admissions. AMI, acute myocardial infarction.

242 to 21 032) stroke hospital admissions had been averted with a reduction of $26.7 \%$.

\section{DISCUSSION}

Based on the information for about 17.7 million insured employees over 54 months, we found that the implementation of the comprehensive tobacco control policy package in Beijing was associated with significant immediate reductions in AMI and stroke hospital admission in population over 18 years old. And it was also associated with a significant change in the secular trend of stroke hospital admissions. These effects mainly benefited from the reductions in both active smoking and SHS exposure. It was reported that the prevalence of smoking among adults in Beijing decreased from $22.8 \%$ in 2014 to $20.3 \%$ in 2017 and the prevalence of SHS exposure also dropped down from $37.9 \%$ in 2014 to $28.2 \%$ in $2017 .{ }^{24}$ Changes in smoking behaviour and
SHS exposure would go a step further to impact health effects. Biological and clinical studies showed that reductions in AMI and stroke events after reduction in exposure to low doses of toxins in tobacco smoke are biologically plausible. ${ }^{557172}$ Even small exposures were shown to increase platelet aggregation and alter endothelial function within $30 \mathrm{~min}$ and induce arterial and haemodynamic changes that can increase the risk of AMI and stroke. $^{53-55}$

Though progresses in tobacco control had been achieved in Beijing, there remained considerable degree of compliance of tobacco control policy to be improved. ${ }^{73}$ According to the adult tobacco survey in Beijing, the rate of supporting public place smoking ban raised significantly after the legislation, the percentage of adults saw tobacco advertisement decreased from $10.9 \%$ in 2014 to $3.7 \%$ in $2016 .{ }^{74}$ Beijing has conducted tobacco control campaign through mass media and new media 
with $29.4 \%$ of adults had ever seen tobacco control information in 2016 from newspaper and magazine, 25.2\% from the broadcast and $48.8 \%$ from the new media. ${ }^{74}$ By the end of 2017 , there were 61 hospitals in Beijing-initiated cessation clinics among which 10 had met the requirement of standardised cessation clinics, providing first contact for 2375 people and pharmaceutical services to 1549 people. There were 20145 person-time received during the smoking cessation counselling service from Beijing's public health service hotline-'12320'. In terms of smoking ban in public places, much less smoking was observed in restaurants (14.8\%) after the enforcement of the policies, ${ }^{75}$ while there remained $48.4 \%$ of conventional cruising taxis that permit passengers to smoke inside their $\mathrm{car}^{76}$ and $80.3 \%$ people still reported being exposed to SHS in bars or nightclubs in 2016. ${ }^{24}$ Although the compliance of policy needed improvement, significant health benefits were still seen. Therefore, we may expect more health benefits from higher compliance of the policy.

According to our results, significant immediate decreases $(-5.4 \%, 95 \% \mathrm{CI}-10.0 \%$ to $-0.5 \%)$ in $\mathrm{AMI}$ admissions were observed right after the policies while no significant change in the secular trend was detected. This is consistent with the study done in England, ${ }^{44}$ Uruguay ${ }^{43} 52$ and Indiana, ${ }^{47}$ while studies conducted in Germany ${ }^{57}$ and New York ${ }^{39}$ found a change in secular trend rather than the immediate reduction. The differences might be explained by the different extents of policy implementation, the changes in SHS exposure and different characteristics of the target population between countries.

For stroke, both immediate change $(-5.6 \%, 95 \% \mathrm{CI}-7.8 \%$ to $-3.3 \%)$ and annual changes in the secular trend $(-15.3 \%$, $95 \%$ CI $-16.7 \%$ to $-13.9 \%$ ) were observed. Previous studies had found inconsistent results in the effect of the smoking ban on stroke. ${ }^{26} \mathrm{~A}$ meta-analysis ${ }^{28}$ and studies in Scotland, ${ }^{77}$ Florida $^{49}$ and Arizona ${ }^{37}$ found significant effects while the study in New York ${ }^{48}$ and Chile ${ }^{41}$ reported no effect. In China, the disease burden of stroke was much higher than in other areas in the world. ${ }^{1378}$ Based on the large sample size of stroke hospital admissions in our study, the results added further evidence to support the effect of the tobacco control policies on stroke.

The results showed differences for annual changes in the secular trend between AMI and stroke. The different results of the two diseases may be explained by three aspects. First, the incidences of stroke and coronary heart disease in adults in Beijing in 2016 were 367.9 and 224.5 per 100 000, respectively. ${ }^{24}$ The disease burden from stroke was much higher than AMI in the study population, providing a greater potential for improvement. Second, in our study the total number of hospital admissions for stroke was three times larger than AMI. It is reasonable to capture any changes for stroke with such a large sample size. Third, more deaths occurred out of the hospital for AMI compared with stroke, ${ }^{79} 80$ therefore, it was more difficult to capture the policy effect on AMI using hospital admission.

Several studies reported diverse health effects in different sexes $^{3844475257}$ and in different age groups ${ }^{3181}$ after the smokefree legislation. The inconsistencies mainly come from the different distribution of social behaviour characteristics, smoking prevalence and SHS exposure between groups. In our study, the effects on stroke were significant among all the age and sex subgroups. For AMI, the lack of significance in the subgroups may be due to the relatively small sample size.

\section{Strengths and limitations}

Based on medical records for about 18 million residents, this study presented an evaluation of the strongest comprehensive tobacco control policy in mainland China. The results provide evidence for the immediate and gradual benefit on the hospital admission of stroke after the implementation of the policy. Compared with previous studies, most of which obtained the data from part of regional hospitals, the current study was based on a database that covered more than $80 \%$ of residents in the area, obtained a large number of stroke hospital records and presented reliable results. Most importantly, as China is the largest consumer of tobacco in the world, the results provide evidence to promote comprehensive tobacco control policies elsewhere, especially in regions with high tobacco consumptions.

There are several limitations in our study. First, though the hospital admission data in the study were obtained from a large claim database covering more than $80 \%$ of residents in the area, it did not cover those aged under 18 years and those unemployed. The interpretation of the results to the whole population needs to be cautious. As the hospital admissions for AMI and stroke in population below 18 years old are low, the health benefit is mainly seen in adults. However, missing unemployed in the database may result in an underestimation of the effect, since this group had higher exposure to tobacco and a higher risk of diseases, and might benefit more from the policy. ${ }^{60}$

Second, during the observation period, no other tobacco control regulation at national level or in Beijing was approved before the intervention. In the postintervention period, two other regulations, the Interim Measures for the Administration of Internet Advertising ${ }^{82}$ and the Provisions of the People's Republic of China on Cigarette Packaging Labeling, ${ }^{18}$ were enforced in national level in September and October 2016, respectively, which may affect the health effects observed in results. The first regulation enforced ban on tobacco advertisement through the internet. According to a monitoring survey conducted by Beijing Center for Disease Prevention and Control, ${ }^{83}$ there were still large amounts of tobacco advertisement and promotion information on the internet after the regulation, indicating the compliance was not high. The second regulation strengthens warning labels on tobacco packaging, but it showed that the strength level of warning labels did not change significantly before and after the policy. ${ }^{84} 85$ Because of the low compliance, we consumed that the health effects following these two regulations were limited. Notwithstanding, we could not exclude the possibility that they bias the effect estimates upward.

Third, in the analysis, despite adjusting for underlying time trends and other covariates, because of the lack of information, there were still some important variables we cannot control for, such as education, cigarette affordability, obesity prevalence, population cholesterol levels and influenza outbreaks, which may influence the results. For example, if the cigarette affordability varies over time, it may confound the impact on admissions mainly related to active smoking. According to the WHO report on the global tobacco epidemic $2019,{ }^{86}$ affordability of cigarette in China had an average change of $-1.6 \%$ over the period 2008-2018. Therefore, without including the cigarette affordability in the analysis might underestimate the policy effect, as the cigarettes affordability in the observational period increased. It is therefore important to raise tobacco tax by considering the growth of income to impact the cigarette affordability.

Lastly, the health benefits of the comprehensive tobacco control policy package will gradually be accumulated as time prolonged. The study period only covered 25 months after the 
policy. Even though, significant health benefits on cardiovascular diseases were seen. The long-term effects on cardiovascular diseases as well as health effects on other diseases following the policy need to be evaluated in further studies exquisitely after a longer observational period.

\section{CONCLUSIONS}

After implementation of the 2015 Beijing comprehensive tobacco control policy package, there were immediate reductions in hospital admissions for AMI and stroke. In addition, the increasing trend of hospital admissions for stroke slowed down after the policy. The results showed significant health benefits on cardiovascular morbidity after the tobacco control policy package which consists of all components of MPOWER in a global city. This study highlighted the importance for a comprehensive policy at the national level in China. Similar comprehensive tobacco control policies are urgently needed in other areas, especially in regions with high tobacco consumptions, to achieve greater public health gains.

\section{What this paper adds}

- Based on medical records for about 18 million residents, this study presented an evaluation of the strongest tobacco control policy in mainland China.

- The results added evidence for the immediate and gradual benefit on the hospital admission of stroke after comprehensive tobacco control policies.

- Following the implementation of tobacco control policy, 18 $137(26.7 \%)$ stroke hospital admissions were likely prevented in 25 months in Beijing.

- The study could provide evidence to promote comprehensive tobacco control policies elsewhere, and inform policymakers regarding comprehensive tobacco control policies, especially in regions with high tobacco consumptions.

Contributors $\mathrm{YH}$ and $\mathrm{CC}$ contributed to the study concept and had full access to all the data in the study. WY and YZ take responsibility for the integrity of the data and interpreted the findings and drafted the article. MW, ZW and SW contributed to data analysis. JW and TW interpreted the data. All the authors contributed to the critical revision of the article for important intellectual content. The corresponding author attests that all listed authors meet authorship criteria and that no others meeting the criteria have been omitted.

Funding The authors have not declared a specific grant for this research from any funding agency in the public, commercial or not-for-profit sectors.

Competing interests None declared.

Patient consent for publication Not required.

Provenance and peer review Not commissioned; externally peer reviewed.

Data availability statement Data are available upon reasonable request. Summarised hospital admission data can be accessed by contacting the National Insurance Claims for Epidemiological Research (NICER) Group, School of Public Health, Peking University. Contact email: 0016156078@bjmu.edu.cn. Air pollution data used in this study can be obtained from the China Environmental Monitoring Center (http://106.37.208.233:20035). Meteorological data can be accessed from the China Meteorological Data Sharing Service System (http:// data.cma.cn/). Particulate matter with aerodynamic diameter $\leq 2.5 \mu \mathrm{m}$ (PM2.5) concentrations can be obtained from the US Embassy report (http://www.stateair. net/web/post/1/1.html). The public holidays can be obtained from the General Office of the State Council of the People's Republic of China (http://english.www. gov.cn).

Open access This is an open access article distributed in accordance with the Creative Commons Attribution Non Commercial (CC BY-NC 4.0) license, which permits others to distribute, remix, adapt, build upon this work non-commercially, and license their derivative works on different terms, provided the original work is properly cited, appropriate credit is given, any changes made indicated, and the use is non-commercial. See: http://creativecommons.org/licenses/by-nc/4.0/.

ORCID iD

Yonghua Hu http://orcid.org/0000-0003-1631-3952

\section{REFERENCES}

1 World Health Organization. Who global report: mortality attributable to tobacco 2012.

2 Barnoya J, Glantz SA. Cardiovascular effects of secondhand smoke: nearly as large as smoking. Circulation 2005;111:2684-98.

3 Borland R, Hyland A, Cummings KM, et al. One size does not fit all when it comes to smoking cessation: observations from the International tobacco control policy evaluation project. Nicotine Tob Res 2010;12 Suppl:S1-3.

4 Thrasher JF, Boado M, Sebrié EM, et al. Smoke-Free policies and the social acceptability of smoking in Uruguay and Mexico: findings from the International tobacco control policy evaluation project. Nicotine Tob Res 2009;11:591-9.

5 WHO. Who report on the global tobacco epidemic, 2019. Geneva: World Health Organization, 2019

6 Hoffman SJ, Poirier MJP, Rogers Van Katwyk S, et al. Impact of the who framework convention on tobacco control on global cigarette consumption: quasi-experimental evaluations using interrupted time series analysis and in-sample forecast event modelling. BMJ 2019:365:12287.

7 World Health Organization. Who report on the global tobacco epidemic, 2017: monitoring tobacco use and prevention policies Geneva 2017.

8 GATS Collaborative Group. Global adult tobacco survey fact sheets 2008-2018 2019. Available: https://nccd.cdc.gov/GTSSDataSurveyResources/Ancillary/Publications.aspx [Accessed 2019/11/19 2019].

9 World Health Organization. Who report on the global tobacco epidemic, 2017: monitoring tobacco use and prevention policies; executive summary. Geneva, 2017.

10 Levy DT, Ellis JA, Mays D, et al. Smoking-Related deaths averted due to three years of policy progress. Bull World Health Organ 2013:91:509-18.

11 Hoffman SJ, Mammone J, Rogers Van Katwyk S, et al. Cigarette consumption estimates for 71 countries from 1970 to 2015: systematic collection of comparable data to facilitate quasi-experimental evaluations of national and global tobacco control interventions. BMJ 2019:365:12231.

12 Chinese Center for Disease Control and Prevention. Survey report on tobacco use among adults in China. China: Chinese Center for Disease Control and Prevention, 2018.

13 Zhou M, Wang H, Zeng X, et al. Mortality, morbidity, and risk factors in China and its provinces, 1990-2017: a systematic analysis for the global burden of disease study 2017. Lancet 2019;394:1145-58.

14 Sturke R, Vorkoper S, Duncan K, et al. Addressing NCDS through research and capacity building in LMICs: lessons learned from tobacco control. Glob Health Action 2016:9:32407.

15 Lv J, Su M, Hong Z, et al. Implementation of the who framework convention on tobacco control in mainland China. Tob Control 2011:20:309-14.

16 Xiao D, Bai C-X, Chen Z-M, et al. Implementation of the world Health organization framework convention on tobacco control in China: an arduous and long-term task. Cancer 2015;121 Suppl 17:3061-8.

17 Congress TtmotscottNPs. Law of advertisement of People's Republic of China, 2015. Available: www.npc.gov.cn/npc/cwhhy/12jcwh/2015-04/25/content_1934594.htm [Accessed 2020/01/01 2020].

18 State tobacco monopoly bureau, General Administration of Quality Supervision, Inspection and Quarantine of the People's Republic of China. Provisions of the people's Republic of China on cigarette packaging labeling, 2016. Available: http:// www.tobacco.gov.cn/html/27/2703/4916673_n.html [Accessed 2020/01/01 2020].

19 People's Government of Beijing Municipality. Beijing's stipulation on the scope of public place smoking ban Beijing, 2008. Available: http://www.beijing.gov.cn/ zhengce/wenjian/192/33/50/438650/75475/index.html [Accessed 2019/03/14 2019].

20 Standing Committee of 14th People's Congress in Beijing municipal. Beijing control smoking ordinance, 2019. Available: http://fuwu.bjrd.gov.cn/rdzw/information/ exchange/Laws.do?method=showInfoForWeb\&id=2014321 [Accessed 2019/11/20 2019].

21 Ministry of Finance, State Administration of Taxation. Notice on the adjustment of cigarette consumption Tax, 2015. Available: http://szs.mof.gov.cn/zhengwuxinxi/ zhengcefabu/201505/t20150508_1229069.html [Accessed 2019/10/07 2019].

22 Mackay J. China: the tipping point in tobacco control. Br Med Bull 2016;120:15-25.

23 Beijing Bureau of Statistics, National Bureau of Statistics Beijing Investigation Team. Beijing statistical Yearbook. Beijing, 2018.

24 People's Government of Beijing Municipality. A report on hygiene and population health status in Beijing. Beijing: People's Government of Beijing Municipality, 2018: 110-1.

25 GBD 2015 Tobacco Collaborators. Smoking prevalence and attributable disease burden in 195 countries and territories, 1990-2015: a systematic analysis from the global burden of disease study 2015. Lancet 2017;389:1885-906. 
26 Frazer K, Callinan JE, McHugh J, et al. Legislative smoking bans for reducing harms from secondhand smoke exposure, smoking prevalence and tobacco consumption. Cochrane Database Syst Rev 2016;2:CD005992.

27 Mackay DF, Irfan MO, Haw S, et al. Meta-Analysis of the effect of comprehensive smoke-free legislation on acute coronary events. Heart 2010;96:1525-30.

28 Tan CE, Glantz SA. Association between smoke-free legislation and hospitalization for cardiac, cerebrovascular, and respiratory diseases: a meta-analysis. Circulation 2012;126:2177-83.

29 Cox B, Vangronsveld J, Nawrot TS. Impact of stepwise introduction of smoke-free legislation on population rates of acute myocardial infarction deaths in Flanders, Belgium. Heart 2014;100:1430-5.

30 Konfino J, Ferrante D, Mejia R, et al. Impact on cardiovascular disease events of the implementation of Argentina's national tobacco control law. Tob Control 2014;23:e6.

31 Thach T-Q, McGhee SM, So JC, et al. The smoke-free legislation in Hong Kong: its impact on mortality. Tob Control 2016;25:685-91.

32 Xiao $\mathrm{H}$, Zhang $\mathrm{H}$, Wang $\mathrm{D}$, et al. Impact of smoke-free legislation on acute myocardial infarction and stroke mortality: Tianjin, China, 2007-2015. Tob Control 2020;29:61-7.

33 Centers for Disease Control and Prevention (CDC). Reduced hospitalizations for acute myocardial infarction after implementation of a smoke-free ordinance--City of Pueblo, Colorado, 2002-2006. MMWR Morb Mortal Wkly Rep 2009;57:1373-7.

34 Abe TMO, Scholz J, de Masi E, et al. Decrease in mortality rate and hospital admissions for acute myocardial infarction after the enactment of the smoking ban law in São Paulo City, Brazil. Tob Control 2017;26:656-62.

35 Bartecchi C, Alsever RN, Nevin-Woods C, et al. Reduction in the incidence of acute myocardial infarction associated with a citywide smoking ordinance. Circulation 2006;114:1490-6.

36 Gasparrini A, Gorini G, Barchielli A. On the relationship between smoking bans and incidence of acute myocardial infarction. Eur J Epidemiol 2009;24:597-602.

37 Herman PM, Walsh ME. Hospital admissions for acute myocardial infarction, angina, stroke, and asthma after implementation of Arizona's comprehensive statewide smoking ban. Am J Public Health 2011;101:491-6.

38 Jan C, Lee M, Roa R, et al. The association of tobacco control policies and the risk of acute myocardial infarction using hospital admissions data. PLoS One 2014;9:e88784.

39 Juster HR, Loomis BR, Hinman TM, et al. Declines in hospital admissions for acute myocardial infarction in New York state after implementation of a comprehensive smoking ban. Am J Public Health 2007;97:2035-9.

40 Liu A, Guzman Castillo M, Capewell S, et al. Reduction in myocardial infarction admissions in Liverpool after the smoking ban: potential socioeconomic implications for policymaking. BMJ Open 2013;3:e003307.

41 Nazzal C, Harris JE. Lower incidence of myocardial infarction after smoke-free legislation enforcement in Chile. Bull World Health Organ 2017;95:674-82.

42 Sargent RP, Shepard RM, Glantz SA. Reduced incidence of admissions for myocardial infarction associated with public smoking ban: before and after study. BMJ 2004:328:977-80

43 Sebrié EM, Sandoya E, Bianco E, et al. Hospital admissions for acute myocardial infarction before and after implementation of a comprehensive smoke-free policy in Uruguay: experience through 2010. Tob Control 2014;23:471-2.

44 Sims M, Maxwell R, Bauld L, et al. Short term impact of smoke-free legislation in England: retrospective analysis of hospital admissions for myocardial infarction. BMJ 2010;340:c2161.

45 Trachsel LD, Kuhn MU, Reinhart WH, et al. Reduced incidence of acute myocardial infarction in the first year after implementation of a public smoking ban in Graubuenden, Switzerland. Swiss Med Wkly 2010;140:133-8.

46 Vasselli S, Papini P, Gaelone D, et al. Reduction incidence of myocardial infarction associated with a national legislative ban on smoking. Minerva Cardioangiol 2008; 56:197-203

47 Weaver AM, Wang Y, Rupp K, et al. Effects of smoke-free air law on acute myocardial infarction hospitalization in Indianapolis and Marion County, Indiana. BMC Public Health 2018;18:232.

48 Juster HR, Loomis BR, Hinman TM, et al. Declines in hospital admissions for acute myocardial infarction in New York state after implementation of a comprehensive smoking ban. Am J Public Health 2007;97:2035-9.

49 Loomis BR, Juster HR. Association of indoor smoke-free air laws with hospital admissions for acute myocardial infarction and stroke in three states. J Environ Public Health 2012;2012:1-5

50 Naiman A, Glazier RH, Moineddin R. Association of anti-smoking legislation with rates of hospital admission for cardiovascular and respiratory conditions. CMAJ 2010;182:761-7.

51 Cronin EM, Kearney PM, Kearney PP, et al. Impact of a national smoking ban on hospital admission for acute coronary syndromes: a longitudinal study. Clin Cardiol 2012;35:205-9

52 Sebrié EM, Sandoya E, Hyland A, et al. Hospital admissions for acute myocardial infarction before and after implementation of a comprehensive smoke-free policy in Uruguay. Tob Control 2013;22:e16-20.

53 Puranik R, Celermajer DS. Smoking and endothelial function. Prog Cardiovasc Dis 2003;45:443-58.

54 Burke A, Fitzgerald GA. Oxidative stress and smoking-induced vascular injury. Prog Cardiovasc Dis 2003;46:79-90.
55 Glantz SA, Parmley WW. Passive smoking and heart disease. mechanisms and risk. JAMA 1995:273:1047-53.

56 Cesaroni G, Forastiere $\mathrm{F}$, Agabiti N, et al. Effect of the Italian smoking ban on population rates of acute coronary events. Circulation 2008;117:1183-8.

57 Sargent JD, Demidenko E, Malenka DJ, et al. Smoking restrictions and hospitalization for acute coronary events in Germany. Clin Res Cardiol 2012;101:227-35.

58 Feigin VL, Nguyen G, Cercy K, et al. Global, regional, and Country-Specific lifetime risks of stroke, 1990 and 2016. N Engl J Med 2018;379:2429-37.

59 Levy D, Rodríguez-Buño RL, Hu T-W, et al. The potential effects of tobacco control in China: projections from the China SimSmoke simulation model. BMJ 2014;348:91134.

60 Verguet S, Tarr G, Gauvreau CL, et al. Distributional benefits of tobacco Tax and smoke-free workplaces in China: a modeling study. J Glob Health 2017:7:020701.

61 Bernal JL, Cummins S, Gasparrini A. Interrupted time series regression for the evaluation of public health interventions: a tutorial. Int J Epidemiol 2017;46:348-55.

62 Robson D, Spaducci G, McNeill A, et al. Effect of implementation of a smoke-free policy on physical violence in a psychiatric inpatient setting: an interrupted time series analysis. Lancet Psychiatry 2017;4:540-6.

63 Tian Y, Liu H, Si Y, et al. Association between temperature variability and daily hospital admissions for cause-specific cardiovascular disease in urban China: a national timeseries study. PLoS Med 2019;16:e1002738.

64 Ab Manan N, Noor Aizuddin A, Hod R. Effect of air pollution and hospital admission: a systematic review. Ann Glob Health 2018;84:670-8.

65 Wu Y, Yang C, Xi H, et al. Prescription of antibacterial agents for acute upper respiratory tract infections in Beijing, 2010-2012. Eur J Clin Pharmacol 2016;72:359-64

66 Cao YY, Xiang X, Song J, et al. Distinct effects of antihypertensives on depression in the real-world setting: a retrospective cohort study. J Affect Disord 2019;259:386-91.

67 Wang J-F, Hu M-G, Xu C-D, et al. Estimation of citywide air pollution in Beijing. PLoS One 2013:8:e53400-e00.

68 Kontopantelis E, Doran T, Springate DA, et al. Regression based quasi-experimental approach when randomisation is not an option: interrupted time series analysis. BMJ 2015;350:h2750.

69 Team RC. R: a language and environment for statistical computing. Vienna, Austria: R Foundation for Statistical Computing, 2019.

70 Wood SN. Generalized additive models: an introduction with R. 2nd edition. Chapman and Hall/CRC, 2017.

71 Benowitz NL. Cigarette smoking and cardiovascular disease: pathophysiology and implications for treatment. Prog Cardiovasc Dis 2003;46:91-111.

72 Law MR, Wald NJ. Environmental tobacco smoke and ischemic heart disease. Prog Cardiovasc Dis 2003:46:31-8.

73 Jiang Q, Jie Z, Rui W, et al. The assessment of tobacco control situation in public places before and after the implementation of the tobacco control regulations in Beijing. Capital Journal of Public Health 2017;11:126-9.

74 People's Government of Beijing Municipality. A report on hygiene and population health status in Beijing. Beijing: People's Government of Beijing Municipality, 2017: 110-1.

75 Xiao L, Jiang Y, Liu X, et al. Smoking reduced in urban restaurants: the effect of Beijing smoking control regulation. Tob Control 2017;26:e75-8.

76 Wu S, Mei H, Liu Z. Results from unannounced visits to check compliance with smokefree regulations in three types of indoor places in Beijing 2018;16.

77 Mackay DF, Haw S, Newby DE, et al. Impact of Scotland's comprehensive, smoke-free legislation on stroke. PLoS One 2013;8:e62597.

78 The GBD 2016 lifetime risk of stroke Collaborators. global, regional, and CountrySpecific lifetime risks of stroke, 1990 and 2016. N Engl J Med 2018;379:2429-37.

79 Commission BMH. Beijing health development Bulletin 2014 Beijing, 2015. Available: www.phic.org.cn/tjsj/wstjgb/201506/t20150605_255023.html [Accessed 2020/04/14 2020]

80 Benjamin EJ, Blaha MJ, Chiuve SE, et al. Heart disease and stroke Statistics-2017 update: a report from the American heart association. Circulation 2017:135:e146-603.

81 U.S. Department of Health and Human Services. The health consequences of Smoking - 50 years of progress: a report of the surgeon General. Atlanta, GA: U.S. Department of Health and Human Services, Centers for Disease Control and Prevention, National Center for Chronic Disease Prevention and Health Promotion, Office on Smoking and Health, 2014.

82 State Administration for Industry. Interim measures on Internet advertising, 2016. Available: http://scjg.fuzhou.gov.cn/zz/xxgk/fgwj/blj//201811/t20181122_2684707. htm [Accessed 2020/01/01 2020].

83 Beijing Center for Disease Prevention and Control,, Peking University. Results release of China's tobacco marketing data on the Internet 2018 Beijing: Sohu, 2019. Available: https://www.sohu.com/a/307998520_120027733 [Accessed 2020/04/01 2020]

84 World Health 0. Who report on the global tobacco epidemic, 2017: monitoring tobacco use and prevention policies. Geneva: World Health Organization, 2017: 135.

85 World Health 0. Who report on the global tobacco epidemic, 2015: raising taxes on tobacco. Geneva: World Health Organization, 2015: 103.

86 World Health Organization. Who report on the global tobacco epidemic, 2019. Geneva: World Health Organization, 2019. 